\title{
PAPER
}

\section{Stability and normal zone propagation in YBCO CORC cables}

To cite this article: M Majoros et al 2016 Supercond. Sci. Technol. 29044006

\section{Manuscript version: Accepted Manuscript}

Accepted Manuscript is "the version of the article accepted for publication including all changes made as a result of the peer review process, and which may also include the addition to the article by IOP Publishing of a header, an article ID, a cover sheet and/or an 'Accepted Manuscript' watermark, but excluding any other editing, typesetting or other changes made by IOP Publishing and/or its licensors"

This Accepted Manuscript is (c) (c) 2016 IOP Publishing Ltd.

During the embargo period (the 12 month period from the publication of the Version of Record of this article), the Accepted Manuscript is fully protected by copyright and cannot be reused or reposted elsewhere.

As the Version of Record of this article is going to be / has been published on a subscription basis, this Accepted Manuscript is available for reuse under a CC BY-NC-ND 3.0 licence after the 12 month embargo period.

After the embargo period, everyone is permitted to use copy and redistribute this article for non-commercial purposes only, provided that they adhere to all the terms of the licence https://creativecommons.org/licences/by-nc-nd/3.0

Although reasonable endeavours have been taken to obtain all necessary permissions from third parties to include their copyrighted content within this article, their full citation and copyright line may not be present in this Accepted Manuscript version. Before using any content from this article, please refer to the Version of Record on IOPscience once published for full citation and copyright details, as permissions will likely be required. All third party content is fully copyright protected, unless specifically stated otherwise in the figure caption in the Version of Record.

View the article online for updates and enhancements. 


\title{
Stability and normal zone propagation in YBCO CORC cables
}

\author{
M. Majoros ${ }^{1}$, M. D. Sumption ${ }^{1}$, E. W. Collings ${ }^{1}$ and D. van der Laan $^{2}$ \\ ${ }^{1}$ Center for Superconducting \& Magnetic Materials (CSMM), The Ohio State University, \\ Columbus, $\mathrm{OH}$, USA \\ ${ }^{2}$ Advanced Conductor Technologies and University of Colorado, Department of Physics, \\ Boulder, CO, USA
}

\begin{abstract}
In this work, a two layer CORC (Conductor On Round Core) cable was tested for stability and Normal Zone Propagation (NZP) at $77 \mathrm{~K}$ in a liquid nitrogen bath. The cable was instrumented with voltage taps and wires on each strand over the cable's central portion (i.e. excluding the end connections of the cable with the outside world). A heater was placed in the central zone on the surface of the cable, which allowed pulses of various powers and durations to be generated. Shrinking (recovering) and expanding (not recovering) normal zones have been detected, as well as stationary zones which were in thermal equilibrium. Such Stationary Thermal Equilibrium zones (STE) did not expand or contract, and hit a constant upper temperature while the heater current persisted; they are essentially a form of Stekly stability. Overall, the cable showed a high degree of stability. Notably, it was able to carry a current of $0.45 I_{c}$ cable with maximum temperature of $123 \mathrm{~K}$ for one minute without damage.
\end{abstract}




\section{Introduction}

High field superconducting magnets require a large number of ampere-turns. To avoid large self-inductances in such magnets they must be wound using superconducting cables. Compared to other currently available high-temperature superconducting (HTS) cables [1 - 10], CORC cables [11] - [14] (see figure 1) have a circular cross-section and the strands of which they are composed are helically twisted around the former. This makes them very suitable for the winding of superconducting magnets. Stability and normal zone propagation (NZP) is crucial in magnet applications. Indeed, NZP is a key parameter determining the magnet's quench protection scheme. In the present paper we measured NZP and more generally quench evolution in a $156 \mathrm{~cm}$ long, 2-layer CORC cable operating in a liquid nitrogen bath at $77 \mathrm{~K}$. During these measurements we tested both cool-down and warm-up cycles, as well as allowable over-currents.

\section{Samples}

The YBCO tape used in the cable was $4 \mathrm{~mm}$ wide and had a nominal critical sheet current density of $25 \mathrm{~A}$ per $1 \mathrm{~mm}$ of tape width in self-field at $77 \mathrm{~K}$. This results in cable nominal critical current of $600 \mathrm{~A}(77 \mathrm{~K}$, self-field). The tape was stabilized by a $20 \mu \mathrm{m}$ thick copper layer that was plated around the tape. The outside dimensions of the $\mathrm{Cu}$-plated tape crosssection were $4.1 \mathrm{~mm}$ in width and $100 \mu \mathrm{m}$ in thickness. Within the cable the tapes were wound helically with their superconducting layer on the inside, i.e. facing the former, to take advantage of their ability to sustain relatively large axial compressive strain without mechanical damage [11] - [14]. The cable used a flexible $5.5 \mathrm{~mm}$ diameter segment of stranded copper as the former; the former was insulated from the tapes. The two layers in the cable were wound with opposite chiralities (helicities). No interlayer insulation was used which allowed some level of current 
sharing between the tapes in the cable. The voltage wires were wound helically along the tapes and placed in the gaps in between them. The parameters of the CORC cable are summarized in Table 1, and the instrumentation of the cable is shown in figure 2. Voltage taps and wires used in the measurements were positioned on each tape over the central portion of the cable $(69 \mathrm{~cm}$ long, section $V x-2$ in figure $2 b$ ). They covered only the superconducting portion of the cable, excluding the resistive joints on both ends of the cable. A heater (42 $\Omega, 5 \mathrm{~mm} \times 5 \mathrm{~mm})$ was placed on top of the cable, positioned in the middle of its length. The tapes were soldered onto the surface of the conical-shaped copper terminals, with their superconducting layer on the inside, using In-Bi-Sn solder (figure 2b).

\section{Experimental}

First we measured the room temperature resistances of each tape in the cable, as determined from the cable current. These results, shown in Table 2, can be used to estimate the cable temperature during NZP experiments above the $T_{c}(90 \mathrm{~K})$ of the YBCO tapes. In case of a stationary NZ they can provide input parameters for equation (2). Using the copper cross-section of the tape and neglecting the contribution of the Hastelloy substrate and buffer layers to the conductivity, we obtain for the tape resistance at room temperature a value of $69.9 \mathrm{~m} \Omega$ (per cable section $69 \mathrm{~cm}$ long, figure 2b)). A parallel connection of six such tapes should have a resistance of $11.65 \mathrm{~m} \Omega$. From Table 2 we see that only tapes in the outer layer of the cable (tape $4,5,6)$ show resistances close to $11.65 \mathrm{~m} \Omega$. Tapes from the inner layer of the cable (tape $1,2,3)$ show significantly lower resistances which might indicate a possible current sharing with the cable copper former. For evaluation of the temperature of the cable above $T_{c}(=90 \mathrm{~K})$ we used the calculated value of the cable room temperature resistance $(11.65 \mathrm{~m} \Omega)$ to calibrate the 
temperature resistance of the cable above $90 \mathrm{~K}$. Temperatures obtained by this procedure are indicated in the figures (where applicable) throughout the paper.

The $I-V$ curves of the tapes in the cable were measured using a sensitive Keithley nanovoltmeter in self magnetic field. NZPs were measured using a multi-channel high-speed data acquisition (DAQ) card controlled via LabView software. Heat was generated by applying a current pulse in the resistive heater. The heater, positioned on the outer surface of the cable (figure 2a), allowed pulses of various powers and durations to be generated at a cable current, during which we applied some percentage of the cable's self-field critical current. During and after the heat pulse NZP was measured by DAQ card.

\section{Results and discussion}

The self-field, DC I- $V$ curves of the individual tapes vs. cable current are shown in figure 3. Critical currents (determined at the electric field criterion of $1 \mu \mathrm{V} / \mathrm{cm}$ ) obtained from them are summarized in Table 3. The average cable critical current is $\left\langle I_{c}\right\rangle=315 \mathrm{~A}$. The maximum $I_{c}$ is 441.51 A (Table 3) which is also the cable critical current. This represents $73.6 \%$ of the cable nominal critical current (600 A). This may be caused partially by the difference in tape self-field compared with the cable self-field or possibly some degradation in winding, handling, or previous measurement. It should be noted that both the $I-V$ curves (Fig. 3) as well as the critical currents obtained from them (Table 3) are determined from the overall cable current, since the currents in individual tapes could not be measured. These numbers reflect the current sharing between individual tapes in the cable, as well as current sharing which is completed within the current lugs of the cable (figure 2). The current sharing between tape 5 and 6 may be responsible for the quasi-linear portions of their $I-V$ curves (between $100 \mathrm{~A}$ and $200 \mathrm{~A}$ ) in figure 3 . These 
quasi-linear parts appear prior to a sharp transition around $200 \mathrm{~A}$. On the other hand a significant difference between the critical currents of tapes 2, 4 (all around $300 \mathrm{~A}$ ) and the critical current of tape 1 and 3 (more than $400 \mathrm{~A}$ ) and $I_{c}$ of the tapes 5, 6 (around $200 \mathrm{~A}$ ) (Table 3, figure 3) may be caused by the current re-distribution within the current lugs of the cable. This current redistribution may be caused by different contact resistances connected in series with the tapes within the cable current lugs [15] measured on the same cable prior to the experiments reported in the present paper. Approximate critical currents of the individual tapes can be estimated as follows. From Fig. 3 and Table 3 we see that tape 5 and 6 have approximately the same critical currents (i.e. $I_{c 5} \approx I_{c 6}$ ). Also we may write $I_{c 2} \approx I_{c 4}$ and $I_{c 1} \approx I_{c 3}$. If we assume that at $200 \mathrm{~A}$ the current is homogeneously distributed among the tapes and the tapes 5 and 6 carry their critical currents, then we obtain $I_{c 5}=I_{c 6}=33.33 \mathrm{~A}$. Similarly if we assume that at 300 A tapes 5 and 6 still carry their critical currents and the rest of the current is homogeneously distributed among the tapes 1, 2, 3 and 4, then we obtain $I_{c 2}=I_{c 4}=58.33 \mathrm{~A}$. Applying the same procedure at $440 \mathrm{~A}$ we get $\mathrm{I}_{\mathrm{c} 1}=\mathrm{I}_{\mathrm{c} 3}=103.33$ A. From this analysis we obtain the cable $I_{c} \approx 389.98$ A which is not too far away from the measured cable critical current of 441.51 A (Table 3). It represents $88.3 \%$ of the measured cable critical current.

After completing $I-V$ curve measurements we started with experiments on NZP and quench systematics. DC transport currents set to be some percentage of the cable critical current $I_{c}$ cable were applied. During and after the heat pulse NZP was measured by a high speed data acquisition card (DAQ) controlled via LabView software. At each DC current $I$ (which was a fraction of the cable critical current) several different experiments were performed with heater pulse currents of different magnitude and duration applied and NZP detected. Combining the heater pulse current magnitude with its duration we were able to detect the onset of the NZP, as 
well as watch it either grow or shrink at different ratios of $I / I_{c}$ cable. This is illustrated in figures 4 -9 .

As seen from figures $4-8$, the differences between tapes seen in figure 3 do not appear at elevated temperatures. This is in accordance with [15] where it is shown experimentally and by modeling that the current distribution becomes homogeneous when the superconducting tapes transit into their normal state. Tape 1 shows a voltage in the middle of the spread of the data (figure $4-8$ ) and tape 5 (figure $6-8$ ) shows the lowest voltage.

Figure 4 and figure 5 represent two different regimes of NZs at $I_{\text {cable }}=100$ A. Figure 4 shows a pulse energy high enough to initiate a normal zone, and once the power application is stopped, the zone shrinks - we are in a recovering zone. Figure 5, with a similar power deposition, but a much longer application time (and thus energy) creates a stationary normal zone. This stationary zone is different from a stagnant zone, in that its temperature does not continually increase. It is apparently in thermal equilibrium, such that the power generated by the $I^{2} R$ in the cable (plus the smaller heater contribution) is exactly matched by the heat removal by the bath. A stagnant zone, on the other hand is spatially confined but has a large and continuing temperature increase, which will lead to burn out. The stationary zone as seen in Figure 5 is relatively benign, and recovers once the power to the heater is switched off. The existence of such a stationary zone phenomenon is essentially a form of Stekly stability, where the heat generation in the conductor is balanced by the heat removal to the cryogen [16]. Looking back to this treatment for LTSC wires, we know that the heat generation per unit length

$$
\dot{G}=\rho \frac{I^{2}}{A_{c u}} \quad \text { and } \quad \dot{Q}={ }_{h} P\left(T_{m}-T_{b}\right)
$$


Where $\dot{G}$ is the power generation, $\dot{Q}$ is the heat removal, $h$ is the coefficient of heat transfer at the cable to liquid nitrogen boundary, $\rho$ is the stabilizer resistivity, $P$ is the perimeter of the cable, $T_{m}$ is the maximum temperature reached, $A_{C u}$ is the cross-section of the cable $\mathrm{Cu}$ stabilizer and $T_{b}$ is the bath temperature. This can be easily solved to find the temperature that the stationary zone will reach

$$
T_{m}=\rho \frac{I^{2}}{{ }_{h} P A_{c u}}+T_{b}
$$

Taking an average voltage of $0.8 \mathrm{~V}$ from figure 5 and an area of 2-times the heater area, then using eq. (2) and heat transfer coefficient given in [17] we get the temperature of the NZ close to $90 \mathrm{~K}$.

Figure 6 shows an existence of recovering NZ at $I_{\text {cable }}=150 \mathrm{~A}$, while figure 7 indicates onset of propagating NZ. Here we see that the criterion for stationary zones can no longer be met, and thus the heat generation must be greater than the potential cooling, even given the large temperature margin. Figure 8 represents an onset of NZ creation at $I_{\text {cable }}=200$ A. Figure 9 demonstrates the cable's high degree of stability - the cable was able to carry the current of $0.45 I_{c}$ with maximum temperature of $123 \mathrm{~K}$ for 1 minute without damage. It is evident that some tapes (1,2 and 3$)$ tend to recover while tapes 4,5 and 6 show a progressive heating. The fact that the tapes 4, 5, and 6 are positioned in outer layers suggest a possibility of additional cooling of tapes 1, 2 and 3 in the inner layer from inside by $\mathrm{Cu}$ former.

Minimum energies of shrinking and expanding NZ creation are summarized in Table 4 and a phase diagram of NZ is shown in figure 10. It is seen that there exists a region with no NZ, and the region of a runaway $\mathrm{NZ}$, as expected. In addition, in a narrow region we see a region 
labeled recovering or stationary normal zone formation. In that case, short energy pulses will lead to recovering zones. Longer pulses may lead to stationary zones, which can be described with the Stekly stability approach. These regimes, of course, are strongly dependent upon the fraction of the cable current to its critical current (figure 10).

\section{Discussion}

The homogeneous model for current distribution among the tapes gives a lower estimate of the temperature (Fig. 9). The maximum voltages in figures 4, 6, 7, 8 are approximately one order of magnitude lower than the voltages in figure 9 . But all of them are orders of magnitude higher than $1 \mu \mathrm{V} / \mathrm{cm}$ (the $I_{c}$ criterion). We can assume that in figure 9 the whole cable length is in normal state. In figure 9, tapes 4, 5, 6 show the same voltage. These tapes are from the outer layer of the cable (in direct contact with $\left.\operatorname{LN}_{2}\right)$. The inner layer tapes $(1,2,3)$ show visibly lower voltages. This is in qualitative accordance with Table 2, where the resistances were measured at room temperature and at a current of about $1 \mathrm{~A}$, so no thermal inhomogeneities or overheatings were present. From Table 2 we see that at $300 \mathrm{~K}$ and low currents (1 A) tapes 4, 5, 6 show significantly higher resistances than tapes $1,2,3$. We ascribe this to possible some level of electrical contact with the cable $\mathrm{Cu}$ core. If we assume (in figure 9) that approximately $1 / 2$ of the cable current is flowing through tapes 4,5 , and 6 then we obtain a resistance close to $300 \mathrm{~K}$. From Table 2 we have the measured resistances on a level of $10 \mathrm{~m} \Omega$ at room temperature, so it can be assumed that they are higher than the resistances in the current lugs. The current lugs are more robust than the tapes so the heating effects in the current lugs should not be too high.

If the resistance of the normal zone at $T_{\max }$ is much higher than the cable end resistance, then even if there are variations in the individual contact resistances, the total circuit resistance of 
a given tape is controlled by the resistance of the normal region, and the tape currents will tend to be self-balancing. That is, the growth of a normal zone in one tape will tend to cause current redistribution in the cable which is effected (i.e., performed) at the cable current in and out junctions. Or, there is current sharing induced by a normal zone which is actually occurring in the cable junctions. This current sharing is kind of artificial, in that it will be a function of measured cable length. So, some strands of the cable may go normal, while others may be still superconducting. This re-balancing should affect the shape of the voltage vs time graph of a quench. It should be that a single strand going normal should have, (a) in the case of a weakly cooled (conduction, or gas) sample a curvature which is concave up, (b) in the case of a better cooled $\left(\mathrm{LN}_{2}\right)$ sample, the curvature, if $J_{e}$ in the $\mathrm{Cu}$ is low enough, and the Stekly conditions can be made to apply, a concave downward curvature, and an eventual saturation, (c) in the case of good cooling and current sharing enabled either along the cable or at the cable ends, an even more concave downward shape, and a saturation level of temperature which is somewhat lower than it would be for inhomogeneous current distribution within the cable.

\section{Conclusion}

Recovering as well as non-recovering NZs have been observed in a CORC cable under quench conditions operating in liquid nitrogen and self-field. In addition, for low $I / I_{c}$ cable, the existence of stationary normal zones in the cable has been seen, which are essentially a form of Stekly stability phenomenon. Several examples of propagating and non-propagating zones were explored at higher $I / I_{c}$ cable fractions, and a stability diagram for the cable was generated. The CORC cable in this study showed a high degree of stability. It was able to carry a current of 45 
$\%$ of the cable critical current with maximum temperature of $123 \mathrm{~K}$ for one minute, without damage.

\section{Acknowledgements}

This work was supported by the U.S. Department of Energy, Office of Science, Division of High Energy Physics, under Grant DE-SC0011721, DE-SC0007891 and DE-SC0014009. 


\section{References}

[1] Takayasu M, Minervini J V, and Bromberg L 2008 Superconductor cable US Patent Application No. PCT/US2009/047961

[2] Takayasu M, Chiesa L, Bromberg L, and Minervini J V 2012 Supercond. Sci. Technol. 25 014011

[3] Takayasu M, Mangiarotti F J, Chiesa L, Bromberg L, and Minervini J V 2013 IEEE Trans Appl. Supercond. 234800104

[4] Takayasu M, Chiesa L, and Minervini J V 2014 IEEE Trans Appl. Supercond. 246600105

[5] Goldacker W, Nast R, Kotzyba G, Schlachter S I, Frank A, Ringsdorf B, Schmidt C and Komarek P 2006 J. Phys.: Conf. Ser. 46901

[6] Long N J, Badcock R, Beck P, Mulholland M, Ross N, Staines M, Sun H, Hamilton J, and Buckley R G 2008 J. Phys.: Conf. Ser. 97012280

[7] Lakshmi L S, Staines M P, Badcock R A, Long N J, Majoros M, Collings E W, and Sumption M D 2010 Supercond. Sci. Technol. 23085009

[8] Terzieva S, Vojenciak M, Pardo E, Grilli F, Drechsler A, Kling A, Kudymov A, Gomory F, and Goldacker W 2010 Supercond. Sci. Technol. 23014023

[9] Vojenciak M, Grilli F, Terzieva S, Goldacker W, Kovacova M, and Kling A 2011 Supercond. Sci. Technol. 24095002

[10] Majoros M, Sumption M D, Collings E W, and Long N J 2014 IEEE Trans Appl. Supercond. 246600505 
[11] van der Laan D C 2009 Supercond. Sci. Technol. 22065013

[12] van der Laan D C, Lu X F, and Goodrich L F 2011 Supercond. Sci. Technol. 24042001

[13] van der Laan D C, Goodrich L F, and Haugan T J 2012 Supercond. Sci. Technol. 25014003

[14] van der Laan D C, Noyes P D, Miller G E, Weijers H W, and Willering G P 2013

Supercond. Sci. Technol. 26045005

[15] Willering G, van der Laan D C, Noyes P, Weijers H, Miller G, and Viouchkov Y 2015

Supercond. Sci. Technol. 28035001

[16] Stekly Z J J, Thome R, Strauss B, 1969 J. Appl. Phys. 402238.

[17] Majoros M, Sumption M D, Collings E W and van der Laan D C, 2014 Supercond. Sci.

Technol. 27125008 


\section{List of Tables}

Table 1. Parameters of the CORC cable used in this study.

Table 2. RT resistance of individual tapes.

Table 3. $I_{c}$ for individual tapes (315 A average).

Table 4. Deposited energies for different NZ types. 
Table 1. Parameters of the CORC cable used in this study.

\begin{tabular}{lllllll}
\hline Cable & Former & $\begin{array}{l}\text { Cable ID } \\
(\mathrm{mm})\end{array}$ & $\begin{array}{l}\text { No. } \\
\text { layers }\end{array}$ & No. tapes/layer & $\begin{array}{l}\text { Total No. } \\
\text { tapes }\end{array}$ & $\begin{array}{l}L_{p} \\
(\mathrm{~mm})\end{array}$ \\
\hline CORC & $\begin{array}{l}\text { Cu, stranded, } \\
\text { insulated }\end{array}$ & 5.5 & $\begin{array}{l}\text { 2, not } \\
\text { insulated }\end{array}$ & 3, not insulated & 6 & 32 \\
\hline
\end{tabular}




1
2
3
4
5
6
7
8
9
10
11
12
13
14
15
16
17
18
19
20
21
22
23
24
25
26
27
28
29
30
31
32
33
34
35
36
37
38
39
40
41
42
43
44
45
46
47
48
49
50
51
52
53
54
56

Table 2. RT resistance of individual tapes.

\begin{tabular}{ll}
\hline Tape & $\begin{array}{c}\text { Resistance } \\
(\mathrm{m} \Omega)\end{array}$ \\
\hline 1 & 1.56 \\
2 & 2.67 \\
3 & 8.75 \\
4 & 10.56 \\
5 & 10.55 \\
6 & 10.55 \\
\hline
\end{tabular}




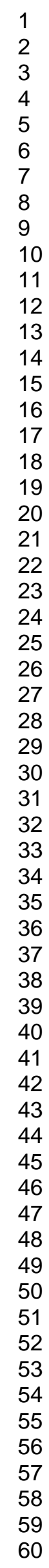

Table 3. $I_{c}$ for individual tapes (315 A average).

\begin{tabular}{ll}
\hline Tape & $I_{c}(\mathrm{~A})$ \\
\hline 1 & 441.51 \\
2 & 337.35 \\
3 & 441.51 \\
4 & 349.35 \\
5 & 213.34 \\
6 & 199.90 \\
Max. & 441.51 \\
& $=I_{c \text { cable }}$ \\
\hline
\end{tabular}


Table 4. Deposited energies for different NZ types.

\begin{tabular}{|c|c|c|c|c|}
\hline $\begin{array}{l}I_{\text {cable }} / I_{c} \\
\text { cable }\end{array}$ & $\begin{array}{l}\text { Max. } \\
\text { energy - no } \\
\text { NZ }(J)\end{array}$ & $\begin{array}{l}\text { Min. energy } \\
\text { recovering or } \\
\text { stationary NZ }(\mathrm{J})\end{array}$ & $\begin{array}{l}\text { Max. energy, } \\
\text { shrinking } \\
\text { NZ }(J)\end{array}$ & $\begin{array}{l}\text { Min. energy, } \\
\text { expanding } \\
\text { NZ }(\mathrm{J})\end{array}$ \\
\hline 0.226 & 40.7 & 42.5 & $>8400$ & \\
\hline 0.34 & 35.3 & 37.0 & 63.5 & 65.9 \\
\hline 0.453 & 35.3 & 35.6 & 35.8 & 36.0 \\
\hline
\end{tabular}




\section{List of Figures}

Figure 1. (a) Two layer CORC cable, $156 \mathrm{~cm}$ long, used in the experiments. (b) A detail view of a section of the cable.

Figure 2. (a) Instrumentation of the cable (photo), (b) Instrumentation of the cable - schematics.

Figure 3. Self-field $I-V$ curves of the cable tapes vs. cable current. Linear portions of $I$ - $V$ curves of tape 5 and 6 (in a range between 100 A - 200 A) may be caused by current sharing among the tapes 5 and 6 within the cable.

Figure 4. NZ with recovery (shrinking NZ): $I_{\text {cable }}=100 \mathrm{~A}, I_{\text {cable }} / I_{\text {c cable }}=0.226, I_{\text {heater }}=1.00 \mathrm{~A} / 5$ $\mathrm{s}$, Deposited energy $=210 \mathrm{~J} / 25 \mathrm{~mm}^{2}$.

Figure 5. NZ with recovery (stationary NZ): $I_{\text {cable }}=100 \mathrm{~A}, I_{\text {cable }} / I_{c \text { cable }}=0.226, I_{\text {heater }}=1.00$ $\mathrm{A} / 200 \mathrm{~s}$, Deposited energy $=8400 \mathrm{~J} / 25 \mathrm{~mm}^{2}$.

Figure 6. NZ with recovery (shrinking NZ): $I_{\text {cable }}=150 \mathrm{~A}, I_{\text {cable }} / I_{\text {c cable }}=0.34, I_{\text {heater }}=0.55 \mathrm{~A} / 5 \mathrm{~s}$, Deposited energy $=63.5 \mathrm{~J} / 25 \mathrm{~mm}^{2}$.

Figure 7. NZ with no recovery (expanding NZ): $I_{\text {cable }}=150 \mathrm{~A}, I_{\text {cable }} / I_{\text {c cable }}=0.34, I_{\text {heater }}=0.56$ $\mathrm{A} / 5 \mathrm{~s}$, Deposited energy $=65.9 \mathrm{~J} / 25 \mathrm{~mm}^{2}$.

Figure 8. NZ with recovery (shrinking NZ): $I_{\text {cable }}=200 \mathrm{~A}, I_{\text {cable }} / I_{\text {c cable }}=0.453, I_{\text {heater }}=0.412 \mathrm{~A} / 5$ $\mathrm{s}$, Deposited energy $=35.6 \mathrm{~J} / 25 \mathrm{~mm}^{2}$.

Figure 9. NZ with no recovery (expanding NZ): $I_{\text {cable }}=200 \mathrm{~A}, I_{\text {cable }} / I_{\text {c cable }}=0.453, I_{\text {heater }}=0.414$ $\mathrm{A} / 5 \mathrm{~s}$, Deposited energy $=36.0 \mathrm{~J} / 25 \mathrm{~mm}^{2}$.

Figure 10. NZ phase diagram. 


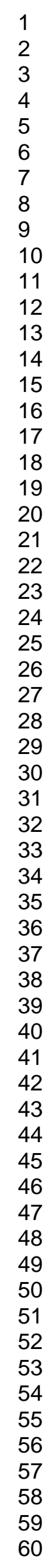




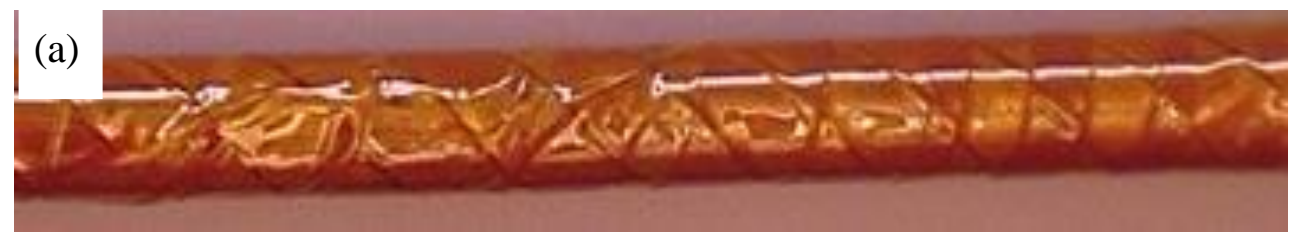

(b)

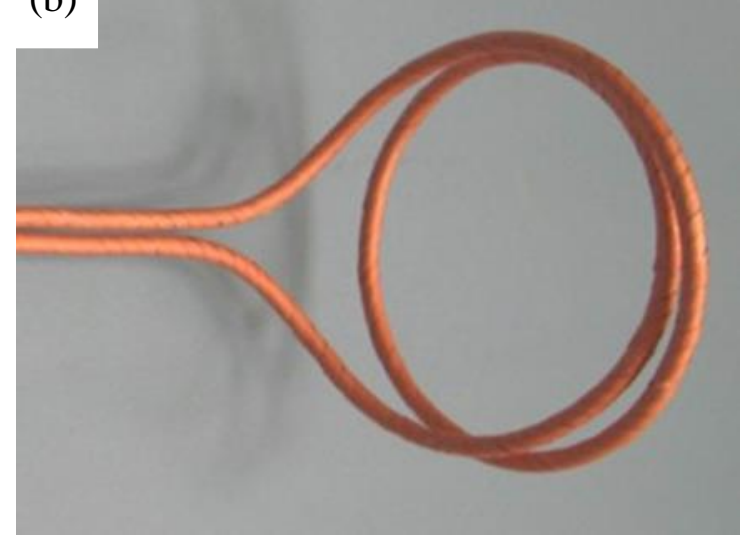

Figure 1. (a) Two layer CORC cable, $156 \mathrm{~cm}$ long, used in the experiments. (b) A detail view of a section of the cable. 

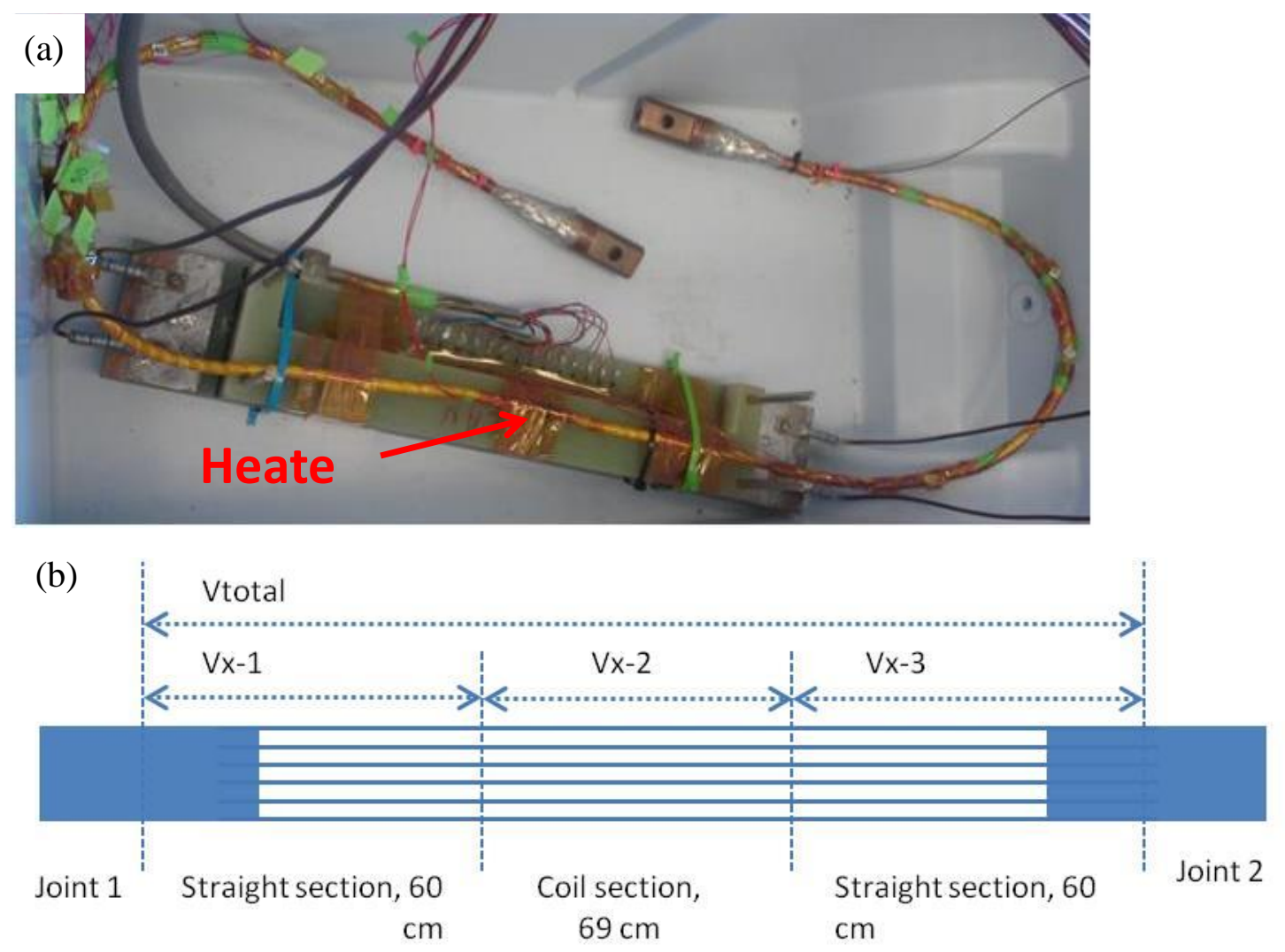

Figure 2. (a) Instrumentation of the cable (photo), (b) Instrumentation of the cable - schematics. 


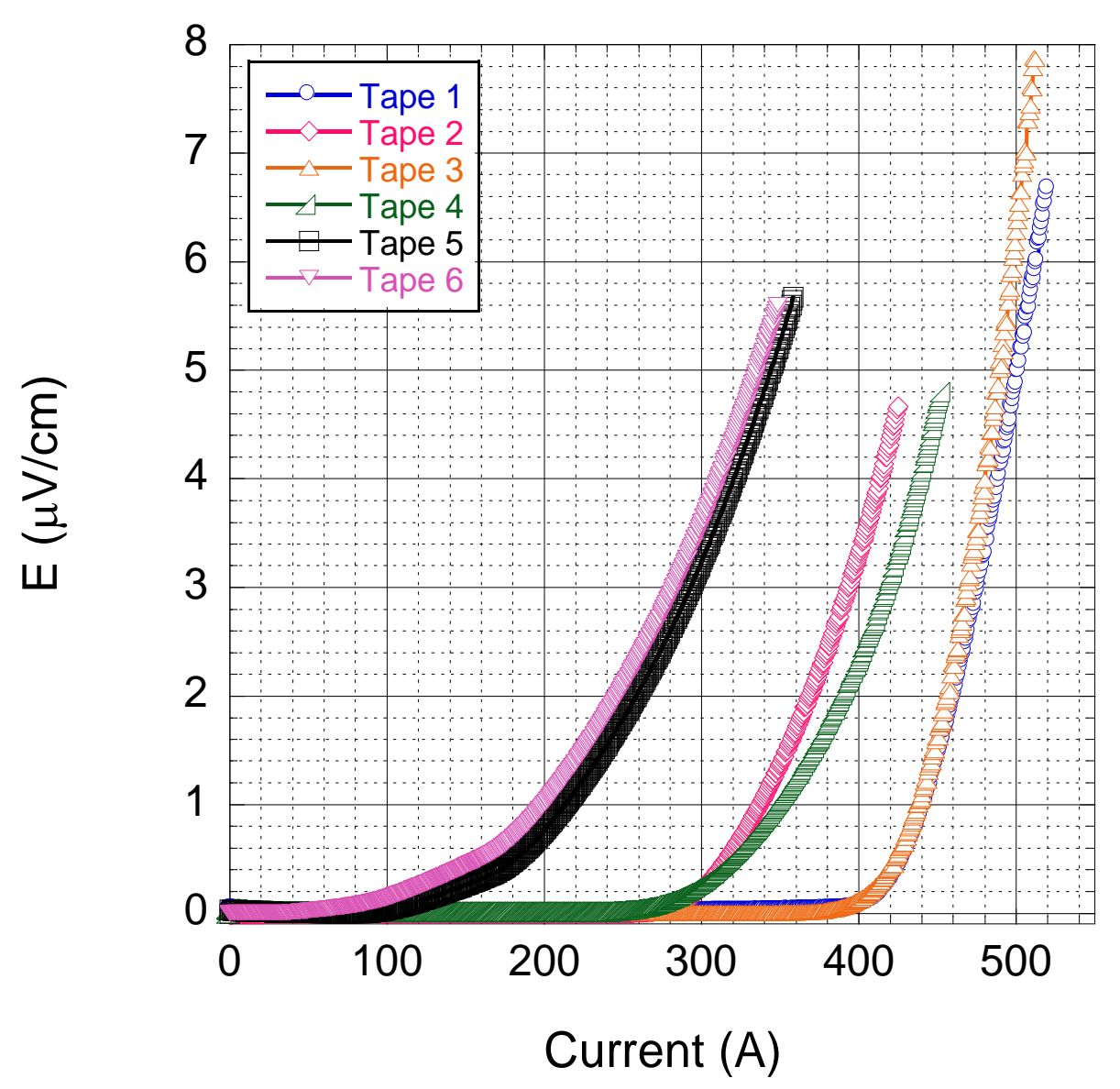

Figure 3. Self-field $I-V$ curves of the cable tapes vs cable current. Linear portions of $I$ - $V$ curves of tape 5 and 6 (in a range between 100 A - 200 A) may be caused by current sharing among the tapes 5 and 6 within the cable. 


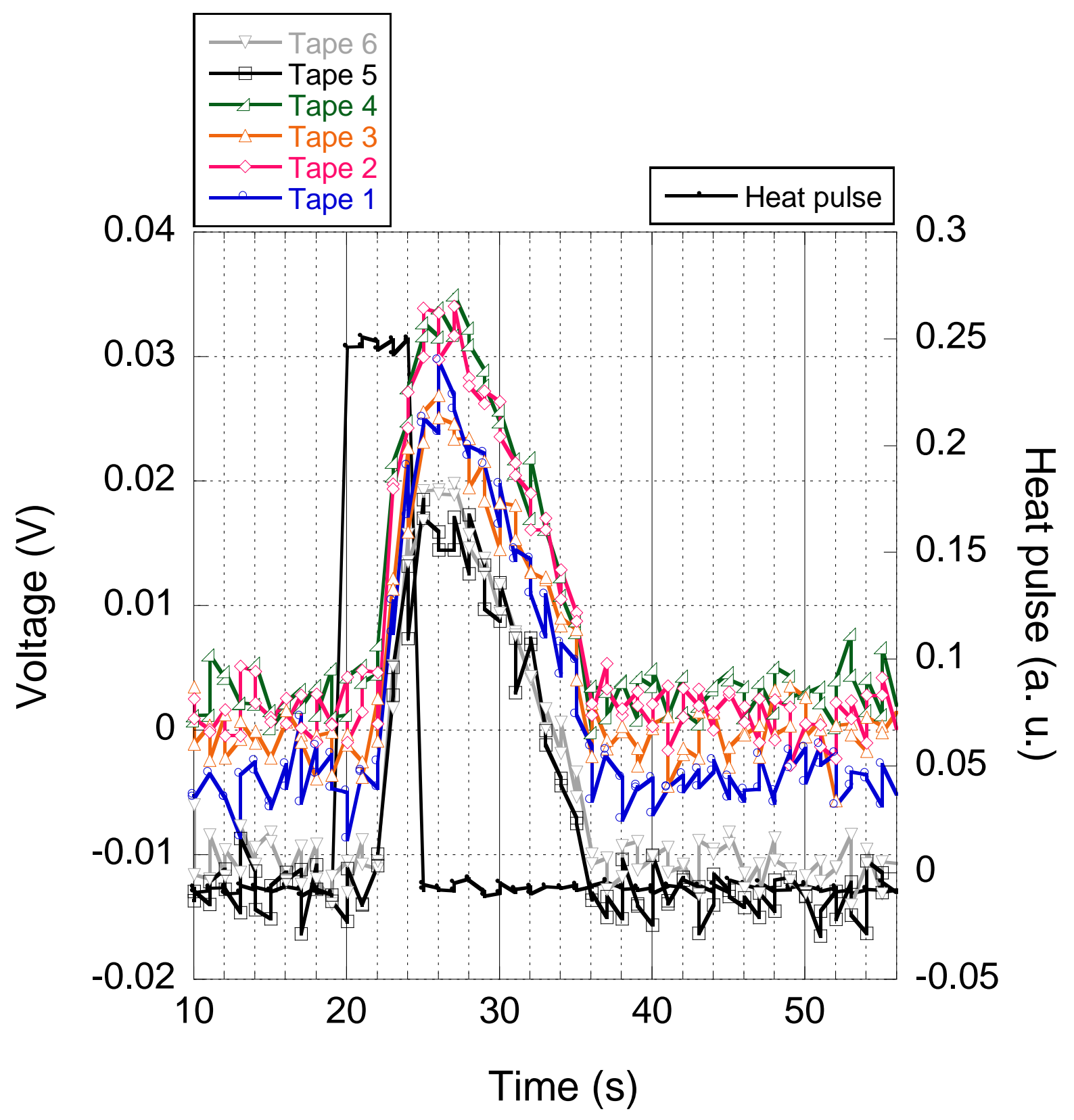

Figure 4. NZ with recovery (shrinking NZ): $I_{\text {cable }}=100 \mathrm{~A}, I_{\text {cable }} / I_{\text {c cable }}=0.226, I_{\text {heater }}=1.00 \mathrm{~A} / 5$ $\mathrm{s}$, Deposited energy $=210 \mathrm{~J} / 25 \mathrm{~mm}^{2}$. 


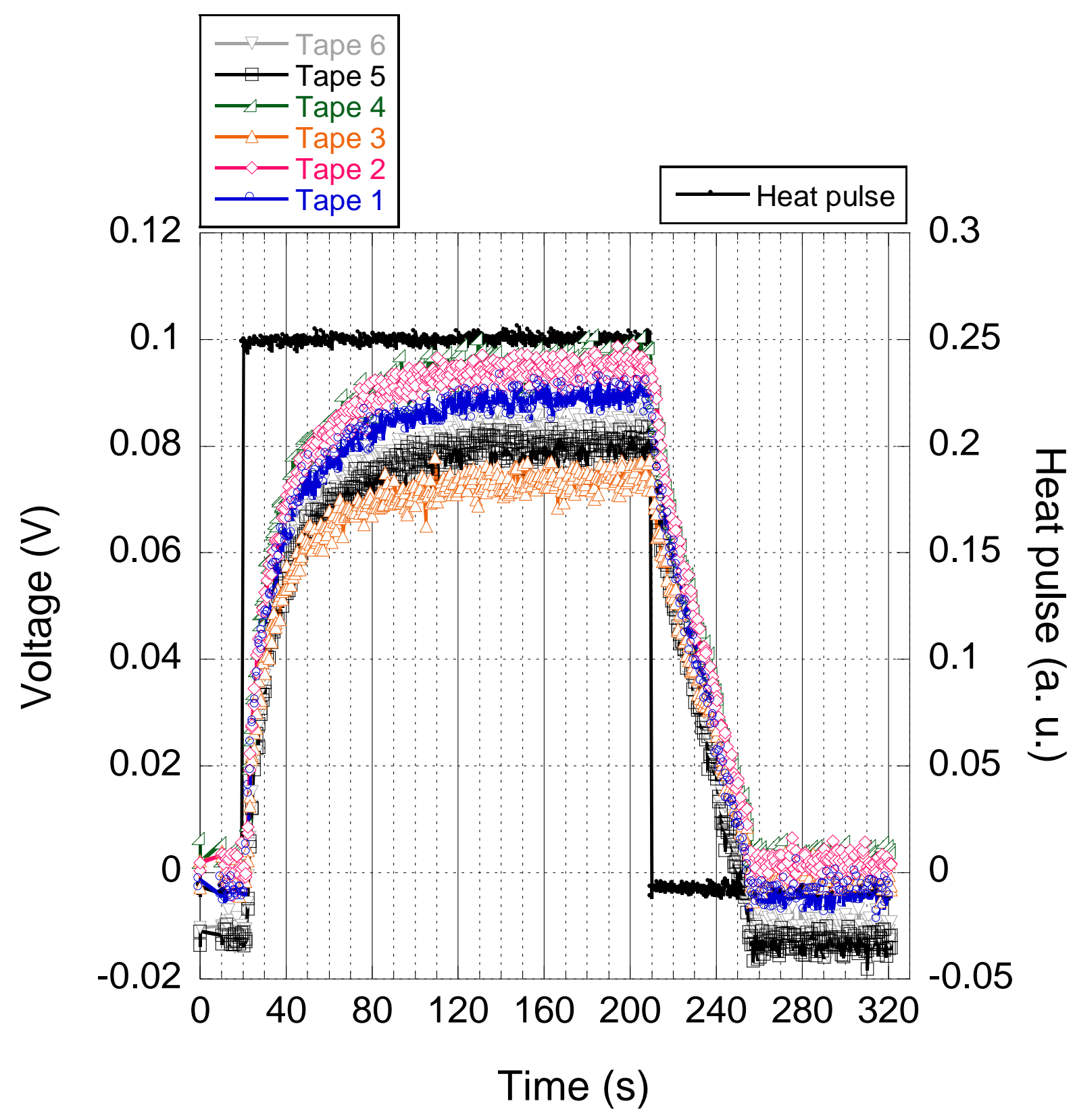

Figure 5. NZ with recovery (stationary NZ): $I_{\text {cable }}=100 \mathrm{~A}, I_{\text {cable }} I_{c \text { cable }}=0.226, I_{\text {heater }}=1.00$ $\mathrm{A} / 200 \mathrm{~s}$, Deposited energy $=8400 \mathrm{~J} / 25 \mathrm{~mm}^{2}$. 


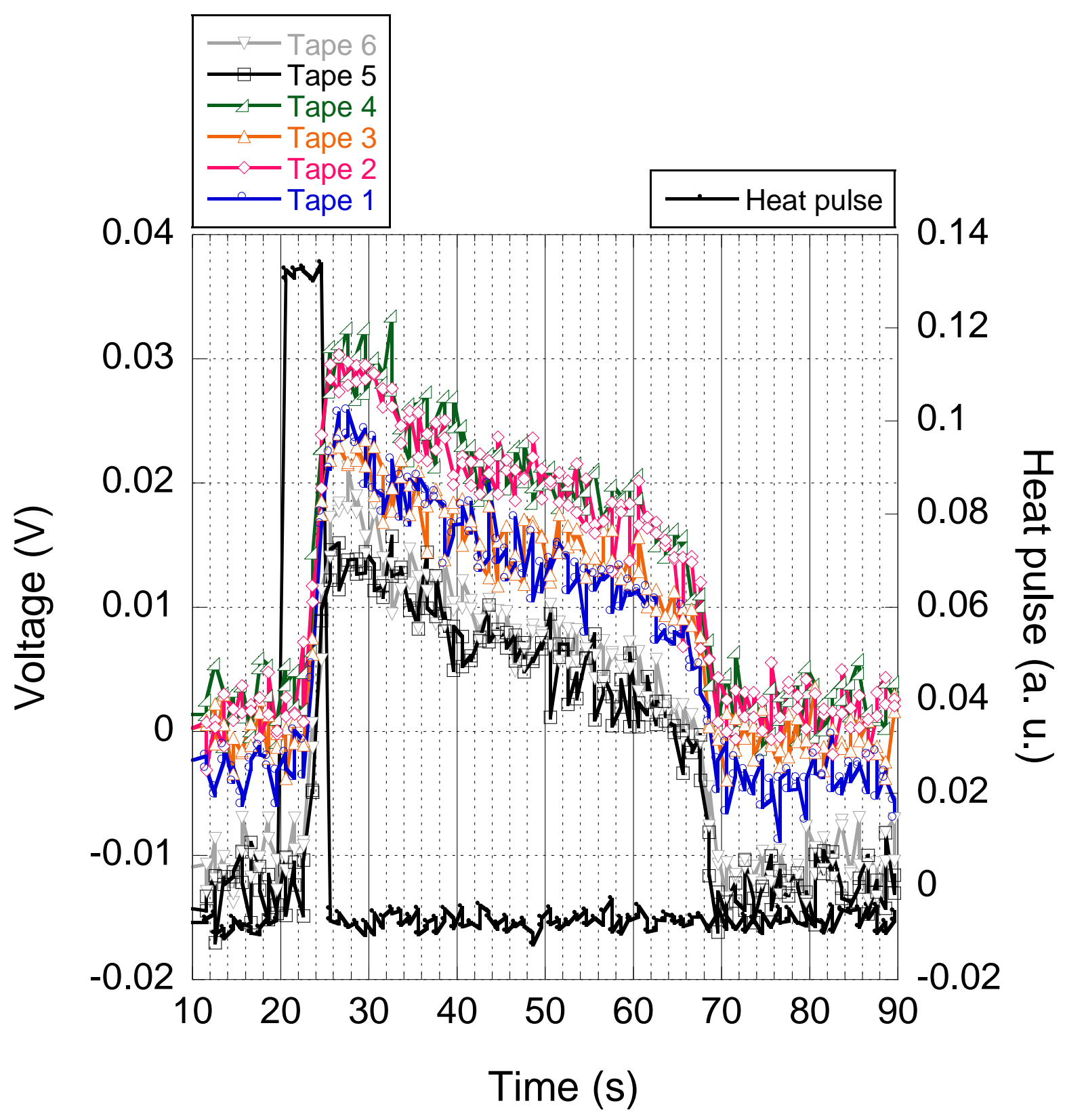

Figure 6. NZ with recovery (shrinking NZ): $I_{\text {cable }}=150 \mathrm{~A}, I_{\text {cable }} / I_{\text {c cable }}=0.34, I_{\text {heater }}=0.55 \mathrm{~A} / 5 \mathrm{~s}$, Deposited energy $=63.53 \mathrm{~J} / 25 \mathrm{~mm}^{2}$. 


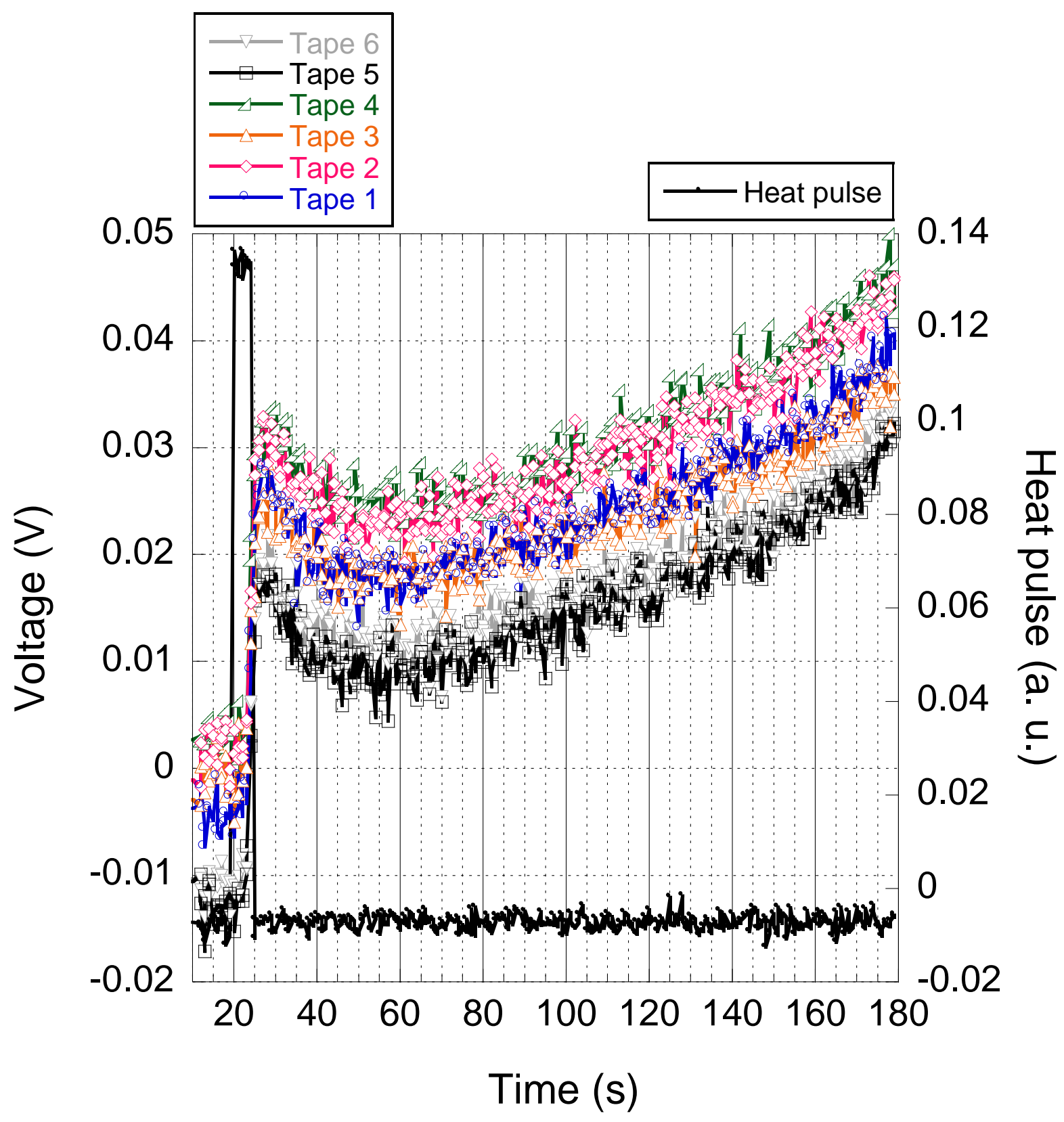

Figure 7. NZ with no recovery (expanding NZ): $I_{\text {cable }}=150 \mathrm{~A}, I_{\text {cable }} / I_{\text {c cable }}=0.34, I_{\text {heater }}=0.56$ $\mathrm{A} / 5 \mathrm{~s}$, Deposited energy $=65.9 \mathrm{~J} / 25 \mathrm{~mm}^{2}$. 


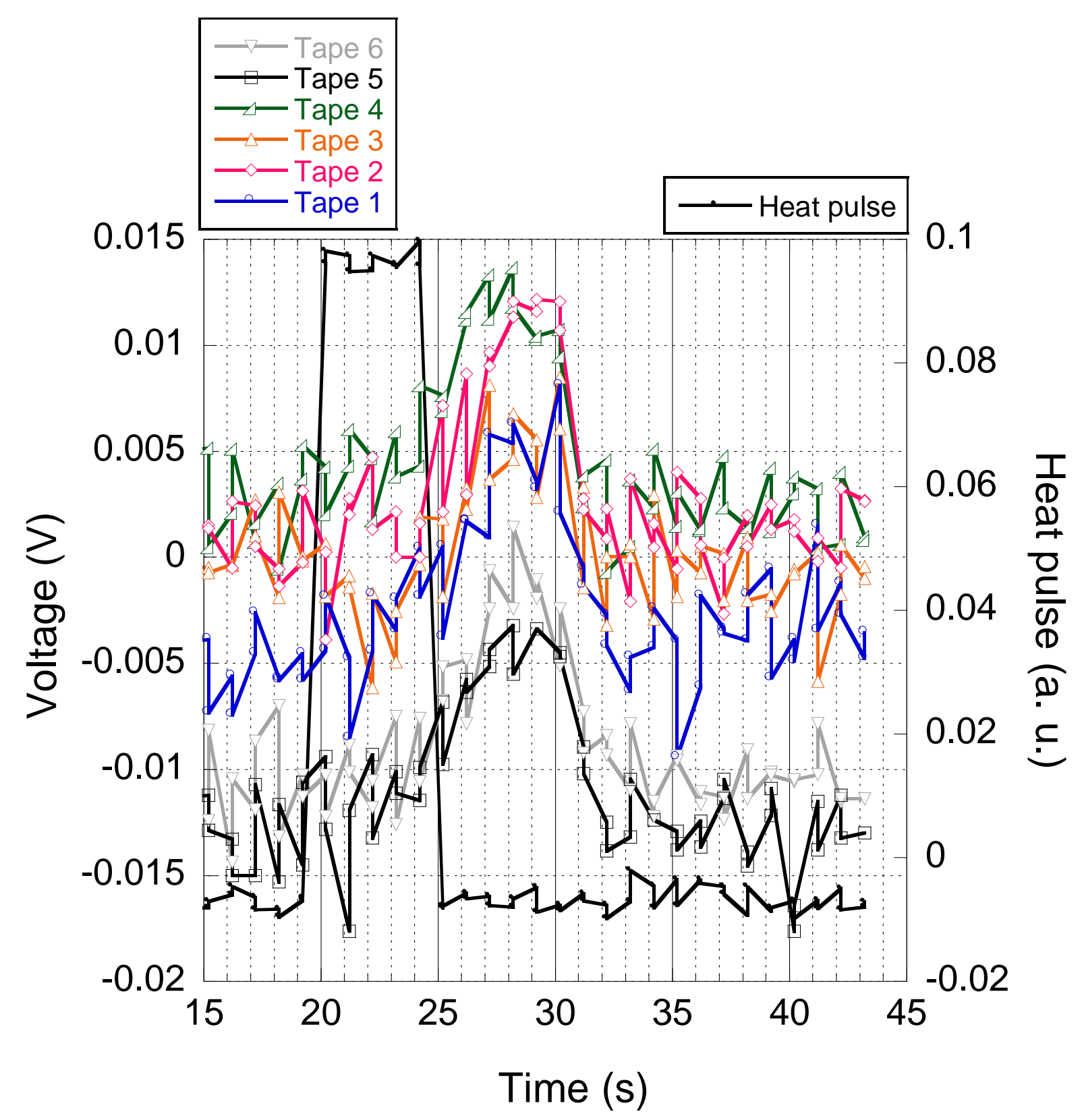

Figure 8. NZ with recovery (shrinking NZ): $I_{\text {cable }}=200 \mathrm{~A}, I_{\text {cable }} / I_{\text {c cable }}=0.453, I_{\text {heater }}=0.412 \mathrm{~A} / 5$ $\mathrm{s}$, Deposited energy $=35.65 \mathrm{~J} / 25 \mathrm{~mm}^{2}$. 


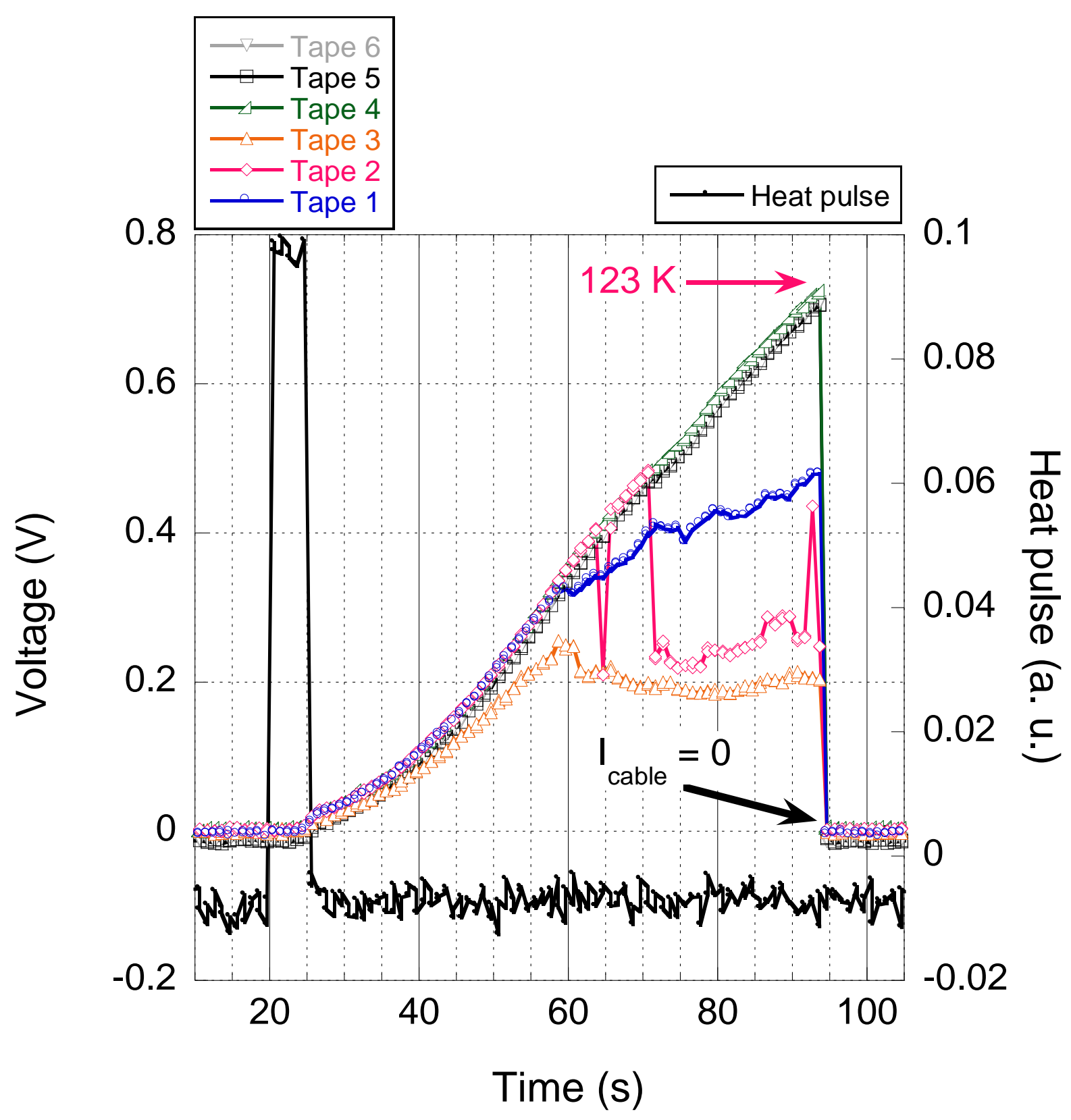

Figure 9. NZ with no recovery (expanding NZ): $I_{\text {cable }}=200 \mathrm{~A}, I_{\text {cable }} / I_{\text {c cable }}=0.453, I_{\text {heater }}=0.414$ $\mathrm{A} / 5 \mathrm{~s}$, Deposited energy $=36.0 \mathrm{~J} / 25 \mathrm{~mm}^{2}$. 


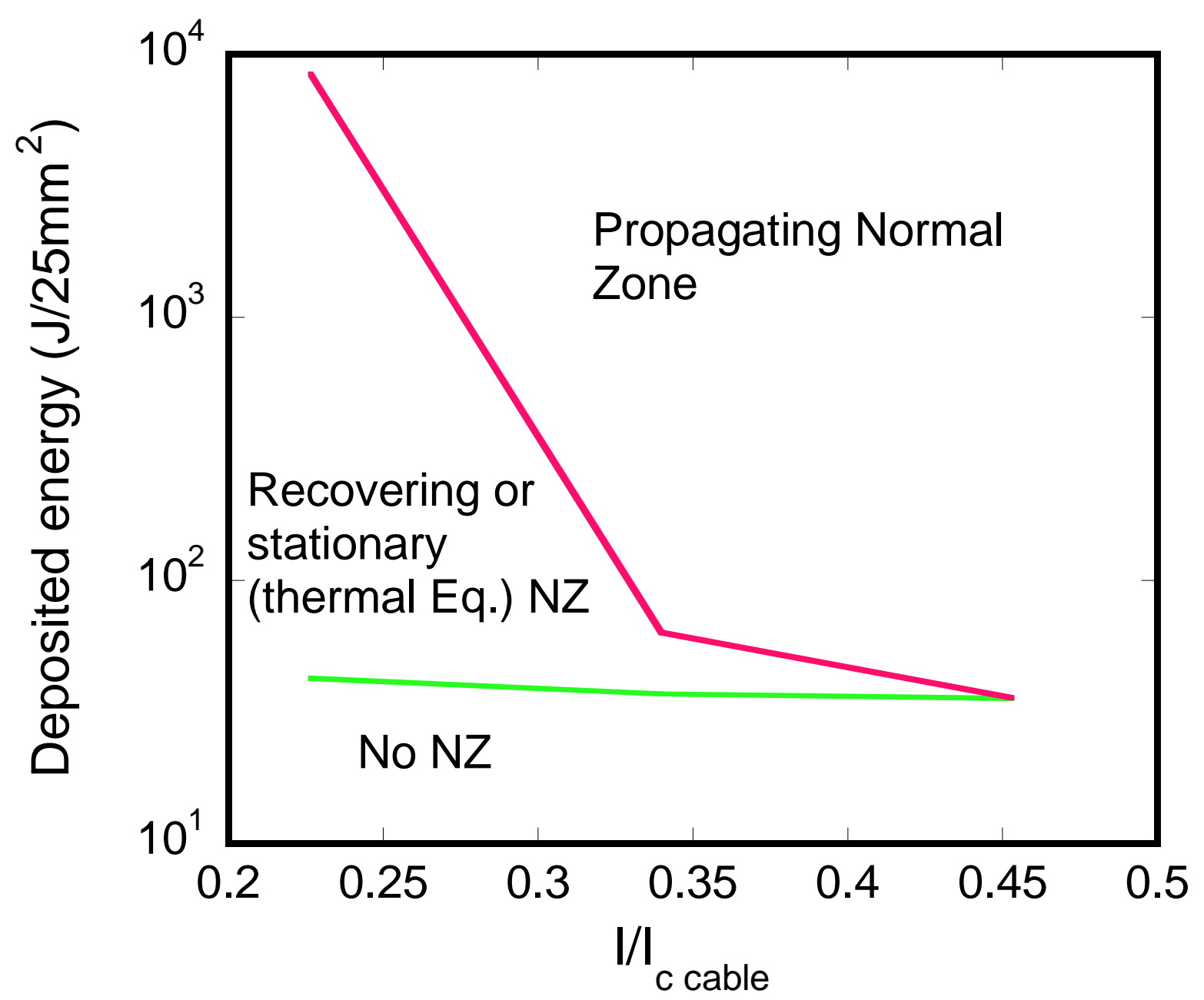

Figure 10. NZ phase diagram. 